\title{
Bushbabies brought to light
}

GENERA

Otolemur, Euoticus, Galago

TAXONOMY

PHYLUM: Chordata

CLASS: Mammalia

ORDER: Primates

FAMILY: Galagidae

\section{Physical description}

Bushbabies, or galagos, are small prosimian primates that are well equipped for their nocturnal and arboreal existence: they have distinctive, round eyes for sharp night vision, large ears for acute hearing and long tails for good balance. The name 'bushbaby' is owed to the animal's vocalizations, thought to sound like the cries of an infant. Bushbabies are omnivorous, eating insects and small animals as well as fruit and tree gum. They have pectinate, or comb-like, incisors that are used in grooming. Fossil studies suggest that this 'toothcomb' arose in bushbaby ancestors in Egypt during the Eocene era, roughly 50 million years ago ${ }^{1}$. Bushbabies today are found primarily in sub-Saharan Africa. The smallest bushbabies are similar in size to chipmunks, with a body length of about 5 in and a tail length of 7 in. The largest bushbabies are closer to opossums in size, with bodies about 12.5 in long and tails roughly 16.5 in long.

\section{Taxonomy}

There are currently about 20 recognized species of bushbabies belonging to three genera: Otolemur includes the greater or thicktailed bushbabies; Euoticus includes needle-clawed bushbabies; and Galago includes the lesser bushbabies. Bushbaby taxonomy is frequently disputed and revised, partly because it can be difficult to distinguish species by morphology alone ${ }^{2}$.

\section{Research résumé}

Bushbabies are used in biomedical research, from neuroscience and behavioral studies to evolutionary and comparative analyses. Recently, the lesser bushbaby Galago senegalensis was included in an assessment of small primate models of aging. Aging studies frequently use rhesus macaques, but smaller animals with shorter lifespans and faster development may be more suitable models. The bushbaby was identified as a promising potential model because of its availability, the existing knowledge about its habits and needs, its potential amenability to genetic manipulation and its physiological similarities to the human with respect to aging ${ }^{3}$.

Another research interest is the risk assessment and foraging behaviors of the greater bushbaby Otolemur crassicaudatus. When foraging for food, bushbabies are faced with multiple threats, including predators and poisonous plants. Researchers have investigated how bushbabies weigh these factors when foraging, comparing their willingness to consume food placed in a tree containing various concentrations of a plant toxin versus food placed on the ground near fresh leopard droppings. The aim of the study was to identify a foraging 'tipping point' at which the bushbabies perceived the danger of eating toxic food as equivalent to the risk of encountering predators. Indeed, the 'tipping point' occurred at a toxin concentration of $5 \%$, illustrating the sophisticated risk assessment that takes place during foraging ${ }^{4}$. This study demonstrates how bushbabies can quantify and compare risks and alter their behavior in response to potential threats.

The bushbaby has also proven useful in comparative genomics studies, in which DNA sequences of different species are matched to each other as a measure of relatedness and as a window into genetic adaptation, species divergence and other evolutionary developments. The genome of the greater bushbaby Otolemur garnettii has been sequenced, albeit at relatively low resolution, as a reference point for comparisons between higher primates (such as macaques, chimpanzees and humans) and non-primate vertebrates (such as rodents). More detailed annotation of the bushbaby genome, as part of a large ongoing sequencing initiative of the National Human Genome Research Institute (http:// www.genome.gov/10002154/), is underway.

1. Seiffert, E.R., Simons, E.L. \& Attia, Y. Fossil evidence for an ancient divergence of lorises and galagos. Nature 422, 421-424 (2003).

2. Nekaris, A. \& Bearder, S.K. The lorisiform primates of Asia and mainland Africa: diversity shrouded in darkness. in Primates in Perspective (eds. Campbell, C.J., Fuentes, A., MacKinnon, K.C., Panger, M. \& Bearder, S.K.) 24-45 (0xford University Press, New York, 2007).

3. Austad, S.N. \& Fischer, K.E. The development of small primate models for aging research. ILAR J. 52, 78-88 (2011).

4. McArthur, C., Orlando, P.A. \& Brown, J.S. Bushbaby foraging ecology: walking the tightrope between predation risk and plant toxins. 5 August 2010. The 95th Ecological Society of America Annual Meeting; 1-6 August 2010; Pittsburgh, PA. 